\title{
FICÇÃO HISTÓRICA, CÓDIGOS NARRATIVOS E MEMÓRIA: a crítica à verdade histórica em Netto perde sua alma ${ }^{I}$
}

\author{
HISTORICAL FICTION, NARRATIVE CODES AND MEMORY : \\ critical to the historical truth in netto perde sua alma
}

Eliza Bachega Casadei ${ }^{2}$

\begin{abstract}
RESUMO: O trabalho tem como objetivo estudar o filme Netto perde a sua Alma a partir do mapeamento dos dois conjuntos de códigos narrativos e estéticos que sustentam a sua narrativa - um deles vinculado a um efeito de real histórico e um outro que engendra os estados de delírio do personagem (colocando a sua narrativa em permanente suspeita) -, bem como os momentos em que essas fronteiras são transpostas. É justamente a tensão entre esses dois sistemas de códigos que constrói a especificidade da representação memorialística em Netto perde a sua alma: trata-se de um filme que, ao mesmo tempo em que se utiliza da referencialidade do discurso histórico e de seus engendramentos próprios de ilusões de real, nega o seu estatuto a partir do engendramento de um outro sistema de códigos socialmente compartilhados que problematiza os aspectos ligados às representações fílmicas do passado.
\end{abstract}

\section{PALAVRAS-CHAVE: Ficção Histórica; Memória; Códigos; Representação do Passado.}

ABSTRACT: This paper aims to study the film Netto perde a sua Alma, mapping the two sets of narrative and aesthetic codes that sustain its narrative - one linked to an historical effect of real and the other one that engenders the states of character delirium (placing his narrative in constant suspicion) - as well as the times that these boundaries between codes are crossed. It is precisely this tension between these two systems of codes that builds the specificity of memory representation in Netto perde a sua Alma: that is a film that, while it uses the referentiality of historical discourse and its own illusions of real, it also denies its status from begetting another socially shared coding system that discusses aspects related to the filmic representations of the past.

KEY-WORDS: Historical Fiction, Memory; Codes; Representation of the Past.

\footnotetext{
${ }^{1}$ Uma versão modificada deste artigo foi apresentada no $16^{\circ}$ Encontro da Socine.

${ }^{2}$ Doutora em Ciências da Comunicação pela Escola de Comunicações e Artes da Universidade de São Paulo (ECA-USP) e professora dos cursos de Comunicação Social do Centro Universitário FIAM-FAAM. É Mestre em Ciências da Comunicação e graduada em Comunicação Social, ambos pela Escola de Comunicações e Artes da Universidade de São Paulo (ECA/USP).
} 
Inserido no gênero da ficção histórica, o filme Netto Perde a sua Alma tem como característica central a projeção de um personagem e de um cenário histórico em uma trama imaginada, o que, enquanto efeito de sentido, “endossa os eventos imaginários com a concretude da realidade enquanto, ao mesmo tempo, endossa os eventos históricos com a 'aura' mágica peculiar à ficção" (WHITE, 1996: 18). Narrado em primeira pessoa, o filme conta a história do general Antônio de Sousa Netto, que lutou na Revolução Farroupilha e na Guerra do Paraguai, à beira da morte em um hospital, de onde relembra os seus principais feitos. Estando o personagem em um estado de perturbação de suas faculdades intelectuais, a trama é desenvolvida a partir de um registro duplo, em que se misturam os fatos históricos com o estado delirante do personagem.

O filme causou certa perturbação no momento de seu lançamento, recebendo uma série de críticas em relação à representação histórica engendrada. Com orçamento de $\mathrm{R} \$ 3,3$ milhões e distribuição nacional e nos países do Mercosul, ele foi exibido pela primeira vez durante a semana das comemorações da Revolução Farroupilha no Rio Grande do Sul e é justamente em relação ao modo como este evento histórico foi retratado que uma série de críticas quanto ao filme se articula.

Para Ricardo Cota (2002), por exemplo, “em relação ao recente cinema brasileiro, Netto Perde sua Alma pode ser considerado um passo atrás”. Isso porque, para o crítico, "há nele tudo aquilo que o próprio cinema nacional já desmitificou: grandiloquência, didatismo, exaltação regional. É mais uma frustrante e desnecessária tentativa de dar um caráter épico à história do Brasil".

Trata-se de um entendimento que se prolongou também para certos círculos acadêmicos. Puhl e Silva (2006) apontam uma série de incorreções históricas presentes no filme como, por exemplo, logo na primeira cena, em que uma tela preta anuncia que "A Guerra dos Farrapos (1835/1845) aconteceu no Rio Grande do Sul. Foi um movimento a favor da República e da abolição, contra o império”, em uma simplificação bastante grosseira acerca do início e das motivações do conflito. Como insistem Puhl e Silva (2006, p. 9):

neste fragmento detectamos uma omissão das principais motivações da revolução. Na época o Rio Grande do Sul sofria com um problema econômico decorrente da taxação excessiva do charque gaúcho 
associado ao estabelecimento de vantagens dadas ao produto importado. Ao mesmo tempo, a elite gaúcha não tinha acesso ao poder político central, basicamente não tinham poder político expressivo, ocasionando a revolução. Com o acordo firmado no final dos dez anos, a elite do RS, obteve mais participação política e uma supertaxação ao charque importado.

Outras cenas são destacadas como, por exemplo, o momento fílmico que sugere que Netto seria o fundador dos lanceiros-negros (ao contrário de correntes historiográficas que apontam Teixeira Nunes como o responsável pela organização) ou, ainda, a cena que mostra a queima da Bandeira Imperial pelo grupo comandado por Netto. Segundo as autoras, não é possível encontrar nenhuma referência histórica que confirme este acontecimento, "assim como é pouco provável que os combatentes teriam junto consigo uma bandeira pronta que seria usada como símbolo da república recém-criada". De acordo com o site oficial do Governo do Rio Grande do Sul, "a primeira aparição da bandeira Riograndense ocorreu quase um mês depois do fato narrado no filme" (PUHL e SILVA, 2006, p. 10).

Tais direcionamentos, contudo, ao criticarem a representação histórica engendrada por Tabajara Ruas, parecem obscurecer aspectos importantes do filme, despojando-o justamente de seu estatuto enquanto ficção histórica. Neste artigo, iremos argumentar que o filme não se pretende enquanto uma representação da verdade histórica, mas sim, que a partir de seus códigos estéticos de narração, engendra justamente uma crítica à verdade histórica em geral.

Ao representar dois estados do personagem, um de lucidez e outro de delírio, em sua tessitura narrativa, o filme engendra dois sistemas de código diversos para retratar cada um destes estados, alicerçando um conjunto de características estéticas específicas para os momentos de calçamento na referencialidade e um outro conjunto distinto para os momentos abertamente ficcionalizados. Há, ainda, momentos em que os dois sistemas de códigos se misturam, engendrando uma indistinção de estados, o que pode ser lido como uma crítica da verdade histórica em geral.

O objetivo do presente trabalho é mapear cada um destes sistemas de código no filme, bem como os momentos em que essas fronteiras são transpostas, tendo em vista uma melhor compreensão das representações memorialísticas no cinema brasileiro e dos engendramentos estéticos utilizados para a apreensão fílmica do passado. 
Por código, iremos nos referir, tal como Barthes (1992), ao movimento de tessitura das vozes dentro da narrativa de um filme que forma uma rede de significação e remete a um inventário das formas narrativas compartilhadas (BARTHES, 1992). A partir do pressuposto de que o código é a instância pela qual as configurações significantes anteriores a um filme tornam-se implícitas na tessitura narrativa, remetendo à história das formas de representação (AUMONT, 1993), o trabalho visa verificar como são articuladas as repetições e as translações de sentido ligadas à representação histórica na composição fílmica, a partir do trabalho com os elementos estético-narrativos em Netto perde a sua alma.

$\mathrm{O}$ estudo dos códigos neste filme remete à própria discussão acerca de como as representações fílmicas da história dizem respeito à manifestação de um sistema de códigos convencionais, uma espécie de gramática onipresente. Nesta lógica, o efeito de referencialidade é construído, justamente, a partir de uma série de procedimentos estilísticos que estão ancorados em regras culturais de representação.

É neste sentido que “o artista realista não coloca de modo algum a 'realidade' na origem do seu discurso, mas apenas e sempre, por mais longe que se pretenda ir, um real já escrito, um código prospectivo, ao longo do qual nunca se avista mais do que uma ilimitada sucessão de cópias" (BARTHES, 1992, p. 173).

Em Netto perde a sua alma, é possível distinguir uma tensão entre os sistemas de códigos que engendram um efeito de realidade (ligados à construção da diegese fílmica a partir de relações de indícios de analogia) e os que engendram um efeito de real (postos nos elementos que tentam conferir um referente empírico à imagem, articulando a ilusão de que o que o espectador vê é a própria realidade histórica tal como aconteceu), como distinguido por Aumont (1995). É justamente essa tensão que constrói a especificidade da representação memorialística em Netto perde a sua alma: trata-se de um filme que, ao mesmo tempo em que se utiliza da referencialidade do discurso histórico e de seus engendramentos próprios de ilusões de real, nega o seu estatuto a partir do engendramento de um outro sistema de códigos socialmente compartilhados que problematiza os aspectos ligados às representações fílmicas do passado. 


\section{A representação histórica e o cinema}

Em sua II Consideração Intempestiva, Friedrich Nietzsche compara a veneração e a constante recorrência ao passado a uma farsa: para ele, o grande perigo do excesso de consciência histórica é que "tudo o que é antigo e passado, enquanto permanece no campo da visão, acaba por ser recoberto por um véu uniforme de veneração, ao passo que aquilo que não dá testemunho de respeito para com estes vestígios, quer dizer, tudo aquilo que é novo e em vias de nascer, se encontra aí atacado e rejeitado" (NIETZSCHE, 2005, p. 94).

Weinrich (2001) comenta que esta apologia do esquecimento do jovem Nietzsche é posta sob determinadas limitações ao longo de seus escritos posteriores. Ao colocar a memória como a base de comunicação entre o devedor e o credor em relação às dívidas (culpas) em sua Genealogia da Moral, ele limita sua exigência por uma arte do esquecimento a partir de razões morais. "Portanto não se trata apenas daquilo que nós - com ou sem arte podemos lembrar ou esquecer, mas também daquilo que - com ou sem arte - precisamos absolutamente lembrar, e talvez, ou talvez não, devemos esquecer” (WEINRICH, 2001, p. 183-185).

A respeito destas considerações intempestivas de Nietzsche, Paul Ricoeur compara esse texto ao Fedro, de Platão. Para ele, Nietzsche situaria "o excesso da cultura histórica do mesmo lado que os grammata incriminados" por Platão e trata "o discurso de defesa do nãohistórico como um equivalente, por assim dizer, pós-historiográfico e pós-historicizante, que o colocaria do mesmo lado que o elogio dirigido por Platão a uma memória anterior à entrada da escrita". A cultura histórica triunfante seria, portanto, o pharmakon nietzschiano (RICOEUR, 2007, p. 303), posto que a história, para Nietzsche, é alocada simultaneamente como dano (afinal, "história demais mata o homem" e "somente o estado absolutamente nãohistórico, anti-histórico, não gera apenas a ação injusta, mas todo ato de justiça") e como necessidade ("em termos de imitação da grandeza, de veneração pelas tradições passadas e no exercício crítico do julgamento"). Em sua condição de pharmakon, Nietzsche traz o tema da história como "remédio do qual não se sabe afinal se é também veneno, em razão de sua aliança secreta com a justiça que condena” (RICOEUR, 2007, p. 308).

As representações simbólicas do passado sempre estiveram neste campo de disputa que toma a representação historiadora ora como um passado que se mostra como uma espécie de "verdade eterna", apoiando em si mesma a sua própria autoridade; ora como a guardiã da 
possibilidade de mostrar um outro olhar sobre o mundo, um olhar que pode mostrar a variabilidade e o devir dos eventos.

Ao comentar a visão nietzschiana sobre os usos da história, Michel Foucault, por exemplo, irá dizer que a história pode se mostrar tanto como "uma verdade eterna, uma alma que não morre, uma consciência sempre idêntica a si mesma", como também mostrar a "acuidade de um olhar que distingue, reparte, dispersa, deixa operar as separações e as margens - uma espécie de olhar que dissocia e é capaz ele mesmo de se dissociar e apagar a unidade deste ser humano que supostamente o dirige soberanamente para seu passado" (FOUCAULT, 1979, p. 13).

Os estudos sobre como os meios de comunicação de massa se apropriam desses eventos do passado não deixam de estar sujeitos a esta noção de pharmakon que os estudos sobre os usos da história sempre carregam.

É a partir desta perspectiva que Napolitano (2007), por exemplo, coloca que o cinema - entendido como uma das principais linguagens artísticas que tentam dar conta da representação do passado - pode apresentar tanto uma monumentalização do decorrido quanto se encarregar da tarefa oposta, ou seja, da desconstrução de monumentos já consolidados. A linguagem do cinema - segundo o autor, espetacular por excelência - encenaria este passado a partir de uma ótica própria do presente e, neste sentido, teria tanto o potencial de construir um lugar de celebração de determinados valores compartilhados, quanto de suscitar uma problematização, a partir deste retorno, de questões sociais sólidas ligadas ao compartilhamento de sentidos.

O filme Amistad (1997), de Steven Spielberg, e Danton (1983), de Andrzej Wajda estão, de acordo com autor, em lados opostos destas possibilidades engendradas pelo cinema. Enquanto o primeiro é construído tal como um monumento da democracia americana, que se mostra capaz de dar voz até mesmo aos oprimidos pela escravidão, o outro (mesmo tendo sido financiado pelo governo Mitterrand com claros objetivos comemorativos, logo, políticos) tenta desmitificar alguns ideais ligados à Revolução Francesa. Amistad parte de uma estratégia fílmica que, "justamente por ser bem sucedida, consegue ocultar sob uma narrativa épica as contradições históricas da democracia liberal nascente" (NAPOLITANO, 2007, p. 74). Já Danton opera uma inversão de alguns mitos historiográficos como a dos heróis revolucionários (mostrados muitas vezes como fracos ou contraditórios) e da participação do 
povo (mostrando mesmo uma revolução sem massas, como um conjunto de decisões e conchavos entre cúpulas).

Também Samuel Paiva compartilha da visão de que o uso da história no cinema, guarda a possibilidade técnica de uma outra utilização das imagens, de uma subversão mesmo dos propósitos para os quais elas haviam sido criadas. Ou seja, de um reaproveitamento que abale as expectativas arraigadas e que possa lançar olhares outros sobre o passado. É o caso, para este autor, dos filmes de Rogério Sganzerla que, através de montagens de imagens dos cinejornais do Departamento de Imprensa e Propaganda de Getúlio Vargas, contrapunha o princípio de eternização do poder para o qual elas haviam sido criadas, em direção a uma noção de história que considerava a realidade em suas perspectivas relativas.

Para Paiva, os filmes de Sganzerla como Nem Tudo é Verdade (1986), Tudo é Brasil (1998) e O signo do caos (2003) subvertem o lugar ocupado pelo herói e recuperam uma dimensão de uma humanidade orientada por conflitos de diferentes dimensões. Assim, na reconstituição da passagem de Welles pelo Brasil, Sganzerla recupera trechos do Cine Jornal Brasileiro, mas de uma maneira subvertida. Mesmo valendo-se de material originalmente concebido como propaganda, "nos filmes de Sganzerla a História se sobrepõe à Eternidade tanto ao privilegiar a contraposição dos pontos de vista para além daqueles comprometidos com os interesses do ditador como ao incluir diferentes vozes implicadas em diversos tempos e espaços envolvidos com os eventos narrados" (PAIVA, 2007, p. 139-140).

De uma maneira geral, Netto perde sua Alma foi interpretado pela crítica como um filme que valorizava a tirania da verdade histórica, ignorando com isso, alguns elementos estéticos centrais do filme. Conforme discutiremos a seguir, o filme pertence a uma tradição fílmica de utilização do passado para a revelação de novos olhares sobre a própria história e, mais especificamente, de um olhar que questiona a própria possibilidade da verdade em todas as representações do passado em geral.

\section{Os dois códigos estéticos de narração em Netto Perde sua Alma:}

Ao estudar o modo como a produção identitária de personagens da ficção cinematográfica pode ser amplificada pelos elementos identitários já possíveis em outros níveis sociais, produzindo novos sentidos e evidenciando o papel da mídia como um 'potencializador' de evocação identitária, Salaini e Carvalho (2008) mostram como a exibição 
do filme Netto Perde Sua Alma foi seguida por um conjunto de manifestações públicas que discutiam alguns eventos históricos retratados no filme. O ator Sirmar Antunes, por exemplo, que no filme representava o Sargento Caldeira, foi aclamado, em 2004, como "lanceiro negro contemporâneo", reacendendo a discussão pública em torno do caso Porongos. "O senador Paulo Paim criou, durante o ano de 2004, o troféu Lanceiros Negros, evidenciando como o 'lanceiro' passa a ser um signo acionado e atualizado em situações diversas" (SALAINI e CARVALHO, 2008, p. 160) ${ }^{3}$. De fato, o filme utiliza uma série de figuras presentes no imaginário gaúcho que parecem reforçar a interpretação ufanista e facilitar a promoção desse tipo de manifestação. Tal como apontado por Pinho (2012), imagens anteriormente presentes na representação tradicional do gaúcho em cancioneiros populares são retomados em Netto Perde Sua Alma como, por exemplo, o fato de Netto ser guerreiro e muito apegado ao campo ou, ainda, o amor de Netto por seu cavalo. "Nos cancioneiros, as principais características do gaúcho são a revolta, o companheirismo, a solidariedade, a rusticidade, a simplicidade, a fidelidade, a força, o cavalo como companheiro inseparável, o gosto pela liberdade, a obstinação à sua sina, a coragem, a valentia, a aversão a estrangeiros, a honra, a dignidade e a solidão" (PINHO, 2012), todas estas características compartilhadas por Netto enquanto personagem fílmico.

\footnotetext{
${ }^{3}$ Além desse episódio específico, as autoras elencam ainda outras manifestações públicas similares que seguiram a esteira de Netto Perde Sua Alma. "Desde então, Sirmar Antunes é chamado a participar - na condição de especialista no assunto - em eventos diversos que discutem a 'controvérsia de Porongos', sendo frequentemente chamado a proferir palestras sobre o tema. (...) Durante as comemorações da Semana Farroupilha de 2005, em Porto Alegre, o ator desenvolveu uma palestra sobre o tema no 'Piquete dos Lanpiários'. Nas instalações do piquete era exibida uma representação de um lanceiro negro baseada na participação de Sirmar em Netto perde sua alma. Nos dias 13 e 14 de novembro de 2004 houve uma série de atividades, na cidade de Pinheiro Machado, Rio Grande do Sul, em homenagem aos lanceiros negros. O ponto alto de tal encontro seria a inauguração, no dia 14, de uma pedra fundamental que serviria de ponto de partida à construção do Memorial aos Lanceiros Negros no Cerro de Porongos, reconhecido como local da batalha e localizado nessa cidade" (SALAINI e CARVALHO, 2008, p. 161). 
A estes códigos narrativos tradicionais, no entanto, o filme parece contrapor uma série de reengendramentos estéticos que, em última instância, acabam por problematizar, justamente, esse primeiro conjunto e por incorporar outros sentidos possíveis à representação histórica que se afastam do ufanismo e da mitologização do personagem. Neste sentido, Netto Perde sua Alma não é um filme de história, mas sim, um filme que se assume enquanto de imaginação histórica, problematizando as representações do passado. Vejamos como isso é articulado esteticamente.

A estória contada por Netto Perde sua Alma se desenvolve narrativamente em dois espaços diegéticos. O primeiro dele se desenrola dentro do hospital Militar de Corrientes, na Argentina, lugar onde Netto se recupera dos ferimentos sofridos durante a Guerra do Paraguai. Pode-se dizer que este simboliza o espaço do delírio, uma vez que, devido ao estado de saúde do personagem, toda a sua narrativa se coloca em um permanente estado de suspeita. É nesse espaço que ele recebe as visitas do personagem Sargento Caldeira, morto há muitos anos, para quem ele conta a sua estória.

O segundo espaço se desenvolve justamente a partir dessa estória contada por Netto e é posto fora do hospital. Trata-se do espaço da memória de Netto, um espaço que diegeticamente se confunde com o registro histórico e se multiplica para uma dezena de outros lugares: é neste espaço que o filme nos mostra as cenas da Revolução Farroupilha, da Guerra do Paraguai, do encontro de Netto com a mulher que seria sua futura esposa na cidade de Paissandu, bem como os vastos cenários naturais do Rio Grande do Sul.

Em sua tessitura narrativa, o filme engendra dois sistemas de códigos estéticos diversos para retratar cada um destes espaços, alicerçando um conjunto de características estéticas específicas para os momentos de calçamento na referencialidade e um outro conjunto distinto para os momentos abertamente ficcionalizados.

Enquanto características estéticas deste espaço do delírio (cenas em que o personagem principal está dentro do hospital), é possível observar que todas as cenas são escuras e utilizam uma matriz de cor azulada. Além disso, todas as cenas são filmadas em planos fechados. Outra característica interessante é o fato de que, nesse espaço, todos os diálogos são conduzidos de forma mais teatralizada e menos naturalista, posto enquanto um elemento de estranhamento. 
Essas características estéticas se mantêm em todas as cenas que se desenrolam no hospital e diferem radicalmente das características estéticas engendradas nos momentos em que o personagem se encontra fora desse espaço.

Nas cenas que retratam a estória contada por Netto (espaço da memória e da história), é possível ver que as características estéticas se estruturam quase de maneira oposta. Todas as cenas são claras e sem a presença do filtro azul característico do espaço anterior. Além disso, todos os planos são abertos, com muitas cenas feitas em panorâmica e com uma exploração bastante marcante das cenas de natureza.

Sobre esse aspecto, inclusive, Freitas e Escosteguy (2006) apontam que os aspectos geográficos adquirem um estatuto de personagem em Netto Perde sua Alma, transformando o pampa em uma paisagem mitológica e supervalorizada no filme. Segundo as autoras, "tanto pela ênfase no cenário quanto através de outros traços identitários regionais, o filme foi considerado pela crítica como ufanista e separatista" (FREITAS e ESCOSTEGUY, 2006, p. 34). Também neste espaço os diálogos se desenvolvem de maneira mais naturalista e menos teatralizada.

É possível observar que o filme engendra, portanto, dois espaços diegéticos distintos, com diferentes características estéticas bem marcadas, que marca cada um dos estados de espírito do personagem: um deles marca o espaço de uma suposta verdade histórica (marcada pelo peso do aconteceu) e outro cuja característica é justamente instaurar um contrato com o espectador que insere o relato no campo da pura ficcionalidade.

A separação entre os regimes estéticos de códigos narrativos se mantém de maneira bastante rígida em grande parte do filme. Até mesmo nas cenas noturnas, é possível observar a manutenção dessas características estéticas gerais em cada um dos espaços compostos pela diegese fílmica.

Existem, contudo, alguns momentos no filme em que a separação estreita entre o espaço do delírio e o espaço da memória é subvertida. É justamente nesses momentos, em que os dois códigos estéticos de narração se misturam, que o peso de testemunho histórico do filme se dilui, ou seja, em que o aconteceu da História é posto em causa e questionado. Todos esses momentos acontecem após a segunda metade do filme (quando a divisão estética dos códigos já está bem marcada para o espectador) e, como discutiremos a seguir, colocam o 
filme não como uma tentativa de mostrar o passado tal como ele aconteceu, mas sim, alocamno nas produções que fazem um questionamento da verdade histórica em geral.

\section{Momentos de mescla de códigos estéticos de narração}

Dentre os movimentos estéticos de problematização histórica de Netto perde sua Alma (que explicitam que o filme trata de uma imaginação histórica, de uma construção que se mostra como tal) existem alguns momentos de quebra da quarta parede que são bastante significativos.

Em uma passagem do filme interpretada pelo ator André Arteche, um dos soldados de Netto é ferido em batalha e a cena se desenrola ao mostrar a agonia do homem, se arrastando pela lama até o derradeiro momento de sua morte. A cena é feita em um plano bem fechado e, conforme o soldado se arrasta, algumas gotículas de barro respingam no vidro da câmera e ali permanecem até o final da cena. Essa passagem, em particular, é interessante, pois possui duas chaves de leitura: uma ligada ao explicitamento da representação e a outra posta pela mistura dos códigos estéticos de narração.

A quebra da quarta parede engendra um efeito de estranhamento, na medida em que denuncia a existência do aparato técnico da câmera, retirando o espectador da diegese fílmica. É como se o filme afirmasse para o espectador, neste instante, tratar-se de um filme, de uma representação inventiva do passado, sem um compromisso com um real histórico, buscando na mostração de sua própria opacidade o seu embasamento em um real inventado.

Essa quebra da percepção ilusionista do cinema nessa cena marca também o início, no filme, de um procedimento em que o diretor irá começar a trabalhar a mistura dos códigos estéticos de narração. Até então, os dois padrões estéticos (um que pertencia ao espaço histórico e outro que pertencia ao espaço do delírio) estavam bem demarcados e separados. Essa é a primeira cena em que há mistura das duas dimensões: o registro é feito em plano fechado (tal como nas cenas de delírio), mas sem a matriz azulada característica das outras cenas (em uma matriz de cor característica das cenas do espaço da história).

A partir de então, embora a divisão dos dois regimes estéticos de narração se mantenha durante a maior parte do filme, passam a ser cada vez mais frequentes as cenas pontuais em que o diretor começa a trabalhar a partir da mescla dos padrões estéticos do 
espaço da história e do espaço do delírio (muitas vezes acompanhado de procedimentos de quebra da quarta parede).

Em uma outra cena, por exemplo, Netto está no hospital conversando com o sargento Caldeira (personagem que está morto e que pertence ao estado delirante de Netto), no momento em que ambos decidem matar o cirurgião do hospital (acusado de maus tratos aos pacientes como a amputação das pernas de um dos internados por vingança, sem necessidade médica). Nesse momento, a câmera percorre o corpo de Netto, em pé, vestindo a sua farda militar, no momento em que faz um discurso bastante inflamado com os seguintes termos:

O Imperador do Brasil me disse que admirava nossa bela Província, mas que padecia muito com o ânimo belicoso dos rio-grandenses. Eu respondi que os rio-grandenses também amavam as belas artes e a democracia, e que também admirávamos essa vida tão lírica da Corte, essa Atenas tropical onde ele reinava tão graciosamente. Mas que tínhamos sustentado duzentos anos de guerras de fronteiras, e que sabíamos que mais guerras ainda viriam. Não éramos belicosos, como ele dizia, porque assim o desejávamos, mas porque, se a uns coube o destino de Atenas, a outros coube o destino de Esparta.

Nessa cena, bastante dramática, ao fazer o seu discurso, Netto olha diretamente para a câmera, para o espectador, explicitando novamente o aparato técnico do cinema na elaboração da imagem. Novamente, há a quebra do contrato de comunicação posto, enquadrando o relato na quebra do espaço diegético.

Os exemplos poderiam ser multiplicados, nesse sentido, porém, um dos momentos mais significativos desta mistura de códigos estéticos acontece justamente na cena final do filme, momento em que a morte de Netto é figurativizada por sua fuga do hospital e por seu encontro com o barqueiro da morte.

Nessa cena, feita ao ar livre, embora não haja a quebra da quarta parede, há a mistura de todos os códigos estéticos de narração anteriormente descritos: a cena é feita em plano aberto (tal como no regime histórico), mas com a matriz de cor azulada característica do plano do delírio. Além disso, há a exploração das cenas da natureza, feita em forma de panorâmicas e um registro duplo da interpretação dos diálogos (feitos ora de forma mais naturalista, ora de forma mais teatralizada).

Os procedimentos estéticos de mistura de códigos que se insinuavam ao longo de cenas pontuais no filme encontram a sua expressão máxima na cena final. 
É a partir desses procedimentos que o filme se coloca enquanto uma produção que se articula a partir da crítica à verdade histórica (e não a partir de uma tentativa pretensiosa de mostrar o passado tal como ele aconteceu, como foi interpretado por alguns críticos).

Em primeiro lugar, ele o faz ao instituir, na primeira metade do filme, dois regimes estéticos de narração bem demarcados: um pertencente ao espaço da história e outro pertencente ao espaço do delírio. A partir da segunda metade do filme, quando esses dois padrões estéticos começam a se misturar (e o próprio aparato técnico do cinema passa a ser explicitado), é como se o diretor questionasse, justamente, a possibilidade de separação entre o regime histórico e o regime ficcional, instaurando uma crítica às representações do passado que tem a pretensão de descrevê-lo de forma fidedigna.

Trata-se de um filme, portanto, sui generis na produção cinematográfica nacional, justamente, por conseguir colocar essa crítica não a partir de um discurso instalado no filme, mas sim, puramente a partir de um trabalho com os seus elementos estéticos - elementos estes que instauram uma quebra entre os efeitos de real do filme (postos nos elementos que tentam conferir um referente empírico à imagem, articulando a ilusão de que o que o espectador vê é a própria realidade histórica tal como aconteceu) e seus efeitos de realidade (ligados à construção da diegese fílmica). Ao explicitamento da representação corresponde um questionamento do real histórico.

\section{Considerações finais}

De acordo com a interpretação de Pereira (2012, p. 60), o livro homônimo de Tabajara Ruas que inspirou o filme Netto Perde sua Alma, já apresentava uma perspectiva de crítica histórica, uma vez que "a forma fragmentária da obra, seu ponto de vista intimista e seu narrador de estatuto por vezes questionável são traços responsáveis pela sua atualidade", uma vez que, "articulam uma visão contemporânea da relação dos sujeitos com o processo histórico, que está se tornando uma experiência cada vez mais individualizada e fragmentária".

Desta forma, “a história é 'destotalizada' em romances como o de Tabajara Ruas, pois, à medida que a história oficial é ironizada, a obra está demonstrando que o que ela está apresentando não é a História (única, verdadeira, soberana), mas uma forma possível e plausível de se contar e interpretar os acontecimentos do passado". E assim, Netto perde sua 
alma engendraria uma tentativa de "reescrever ou reapresentar o passado na ficção e na história é - em ambos os casos - revelá-lo ao presente, impedi-lo de ser conclusivo e teleológico" (PEREIRA, 2012, p. 62).

Muitas interpretações sobre o filme Netto perde sua Alma não levaram em consideração esses elementos de crítica à verdade histórica, presentes já no romance que inspirou o filme. Mesmo para Pereira (2012, p. 61):

Ao fim e ao cabo, a adaptação provou ser bem mais conservadora em sua representação do passado e em sua forma e conteúdo quando comparada com seu romance de origem. Como já foi demonstrado em detalhes em outra publicação, o mundo bem organizado e objetivado do filme é uma alusão reverente e comemorativa a tudo o que já é conhecido e difundido (tanto textualmente como em forma de imaginário coletivo) sobre a participação heroica de Netto na Revolução Farroupilha, e, nesse sentido, propõe uma representação idiossincrática do passado, na medida em que reitera e expande o teor dos textos clássicos de história, sem, contudo, ampliar nossa compreensão a respeito das reais condições sociais, econômicas e políticas do acontecimento histórico em si.

A nosso ver, interpretações como essa ignoram o fato de que, da mesma forma como fez com o seu livro, Tabajara Ruas também engendra uma crítica à verdade histórica em seu filme, porém, dada a impossibilidade de utilizar os recursos estruturais disponibilizados pela literatura, ele o faz a partir dos elementos estruturais do cinema, a partir do engendramento de diferentes códigos estéticos de narração próprios à linguagem cinematográfica.

A delimitação precisa, em Netto perde sua Alma, de um conjunto de códigos para os momentos fílmicos que buscam retratar uma suposta verdade histórica e de um outro conjunto de características estéticas para os momentos de delírio e ficcionalidade, são engendrados, no filme, apenas com o objetivo de serem subvertidos posteriormente. A mistura entre os dois conjuntos de códigos estéticos de narração acabam por articular uma crítica à verdade histórica em geral, ao postular, a partir dos elementos estéticos, que esses dois regimes (da realidade e da ficcionalidade) nunca podem ser rigidamente separados.

\section{REFERÊNCIAS}


AUMONT, Jacques. A Imagem. Campinas: Papirus, 1993.

AUMONT, Jacques. A Estética do Filme. Campinas: Papirus, 1995.

BARTHES, Roland. O Rumor da Língua. São Paulo: Brasiliense, 1988.

BARTHES, Roland. S/Z. Rio de Janeiro: Nova Fronteira, 1992.

COTA, Ricardo. "O cinema perde sua alma". Disponível em http://www.criticos.com.br/criticas/critica_interna13.asp. Acesso em 18/01/2012.

FOUCAULT, Michel. Microfísica do Poder. Rio de Janeiro: Graal: 1979.

NAPOLITANO, Marcos. "A escrita fílmica da história e a monumentalização do passado: uma análise comparada de Amistad e Danton". In CAPELATO, Maria Helena, MORETTIN, Eduardo, NAPOLITANO, Marcos e SALIBA, Elias Thomé (org.). História e Cinema. São Paulo: Alameda, 2007.

NIETZSCHE, Friedrich. "II Consideração Intempestiva sobre a Utilidade e os Inconvenientes da História para a Vida". In SOBRINHO, Noéli Correia de Melo (org.). Escritos sobre História: Friedrich Nietzsche. Rio de Janeiro, São Paulo: Editora PUC-Rio e Loyola, 2005.

PAIVA, Samuel. "A representação da realidade em filmes de Rogério Sganzerla: construindo a história a partir de Orson Welles e de cinejornais". In CAPELATO, Maria Helena, MORETTIN, Eduardo, NAPOLITANO, Marcos e SALIBA, Elias Thomé (org.). História e Cinema. São Paulo: Alameda, 2007.

PEREIRA, Mateus da Rosa. "Intertextualidade, Metaficção historiográfica e paródia pósmoderna em diálogo com a tradição dos romances históricos em Netto Perde sua Alma". Graphos, v. 14, n. 1, 2012, p. 60-69.

PINHO, Louise Silva do. "A representação do gaúcho: do cancioneiro à contemporaneidade". In: Linguagem, Educação e Memória, edição 2, v. 1, Novembro de 2012, p. 1-15.

PUHL, Paula e SILVA, Cristina Ennes da (2006). "A imagem ficcional como mediadora do conhecimento". UniRevista, v. 1, n. 3, Julho de 2006, p. 1-13.

RICOEUR, Paul. A Memória, a História, o Esquecimento. Campinas: Editora da Unicamp, 2007.

SALAINI, Cristian Jobi e CARVALHO, Ana Paula Comin de. "Memória, mídia e imaginário social: o caso Porongos". Ilha, v. 10, n. 2, 2008, p. 155-173.

WEINRICH, Harald. Lete: arte e crítica do esquecimento. Rio de Janeiro: Civilização Brasileira, 2001.

WHITE, Hayden. "The modernist event". In SOBCHACK, Vivian (ed.). The Persistence of History: cinema, television and the modern event. New York: Routledge, 1996. 